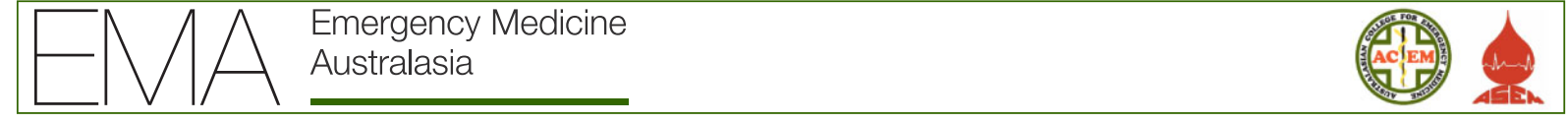

Don't Forget the Bubbles

\title{
Sticks and stones may break some bones
}

Andrew Tagg, ${ }^{1}$ Henry Goldstein, ${ }^{2,3}$ Tessa Davis ${ }^{4}$ and Ben Lawton ${ }^{2,3,5}$

$=$

1. Emergency Department, Footscray Hospital, Melbourne, Victoria, Australia

2. Emergency Department, Lady Cilento Children's Hospital, Brisbane, Queensland, Australia

3. School of Medicine, University of Queensland, Brisbane, Queensland, Australia

4. Emergency Department, Sydney Children's Hospital, Sydney, New South Wales, Australia

5. Emergency Department, Logan Hospital, Logan City, Queensland, Australia $\longrightarrow$

Correspondence: Dr Tessa Davis, Emergency Department, Sydney Children's Hospital, High

Street, Randwick, NSW 2031, Australia. Email: tessardavis@me.com

Andrew Tagg, BSc (Hons), MBBS, MRCSEd A\&E, FACEM, Emergency Physician; Henry Goldstein, BPharm (Otago), MBBS (QLD), Paediatric Registrar; Tessa Davis, BSc (Hons), MBChB, MA, MRCPCH, Paediatric Registrar; Ben Lawton, BSc (Hons), MBChB, FRACP (PEM), Paediatric Emergency Physician.

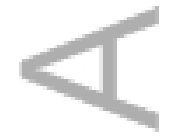

This is the author manuscript accepted for publication and has undergone full peer review but has not been through the copyediting, typesetting, pagination and proofreading process, which may lead to differences between this version and the Version of Record. Please cite this article as doi: $10.1111 / 1742-6723.12531$

This article is protected by copyright. All rights reserved. 
Don't Forget the Bubbles (www.DontForgetTheBubbles.com) is a paediatric educational website providing free online content aimed at healthcare professionals.

\section{Introduction}

Up to a quarter of the paediatric population of the United Kingdom present to an emergency department annually ${ }^{1}$ with a large number being due to falls. ${ }^{2}$ High risk activities such as scooter riding, climbing on monkey bars and backyard trampolines are partially to blame though the implementation of safety netting for trampolines has led to a reduction in injuries. ${ }^{3}$

In this article we seek to explore how a child with a simple forearm fracture is treated. We focus on how we look after their pain, how we make the diagnosis and how we might manage their fracture once it has been diagnosed.

\section{Providing pre-emptive analgesia}

A recent study found that only $76 \%$ of children with significant upper limb fractures received any analgesia within their first hour in hospital. ${ }^{4}$ Appropriate analgesia can begin in the prehospital phase. ${ }^{5}$ Both intravenous opiates and inhalational analgesia such as methoxyflurane have been trialled without serious adverse effects. ${ }^{6}$

Assessment of pain can be challenging in children so it is often under-recognised. The WongBaker faces pain scale ${ }^{7}$ may be used in children over three year old, but use of this scale is unreliable in pre-verbal children, in whom the Faces, Legs, Activity, Cry, Consolability (FLACC) score may be more helpful. ${ }^{8}$ Subjective measures such as changes in physiological parameters 
(pulse, respiratory rate or blood pressure) can add to nurse or physician gestalt. Despite these tools, children are routinely under-treated. ${ }^{9}$

The $\mathrm{WHO}$ analgesia ladder is an appropriate starting point ${ }^{10}$ with rapid escalation as required. Whilst it suggests the addition of mild opioids for moderate to severe pain, the use of codeine as an adjunctive agent has been linked with fatalities in patients subsequently found to be rapid or ultra-rapid metabolizers. ${ }^{11}$ Given that it is also ineffective in $10 \%$ of the population its use should be de-emphasised. Children with moderate to severe pain may be more effectively treated with an alternative agent such as intranasal fentanyl.

Intranasal medication obviates the need for potentially distressing intravenous access. A Cochrane Collaborative analysis suggested that there was little evidence to suggest that intranasal fentanyl was any better, or worse, than intravenous morphine, and it was well tolerated by patients. ${ }^{12}$ Use of a specific intranasal fentanyl pathway could speed up the delivery of analgesia. ${ }^{13}$

Other agents such as sub-dissociative doses of ketamine have also been trialled as an opioid sparing measure. ${ }^{14}$ The PICHFORK trial compared intranasal fentanyl at doses of $1.5 \mathrm{mcg} / \mathrm{kg}$ with intranasal ketamine at $1 \mathrm{mg} / \mathrm{kg}$ in children aged 3-13 years with isolated limb injury and found similar reduction in pain scores 30 minutes post treatment. ${ }^{15}$ With children increasing in size, one should be aware that a number of agents such as paracetamol and morphine should be dosed according to ideal rather than actual body weight. Generally if the ideal weight is more 
than $40 \mathrm{~kg}$ then an adult dosing regime can be used. The exception to this is paracetamol (acetaminophen), with which $15 \mathrm{mg} / \mathrm{kg}$ should be used up to $65 \mathrm{~kg}$ to avoid toxicity. ${ }^{16}$

\section{Non-pharmacological options}

Weight-based doses of analgesia are the mainstay of treatment but a number of nonpharmacological approaches may also be used to reduce both pain and anxiety. If the limb has not been immobilised in a splint it may help to do so prior to imaging.

We know that distraction therapy such as bubbles, music and television screens can also allay some anxiety. ${ }^{17}$ It is easy to put an iPad with an episode of a popular children's television program in front of a crying child in an attempt to distract them but these passive distraction techniques are less effective than using more interactive games. ${ }^{18}$

\section{Making the diagnosis}

If the limb is obviously deformed then making the diagnosis is easy. When there is enough clinical suspicion to suspect a fracture, the majority of clinicians instinctively reach for the x-ray request form. In children we use the ALARA approach to imaging - using As Low As Reasonably Achievable a dose of radiation to reduce radiation exposure. ${ }^{19}$ Ultrasound has been successfully used to detect a number of fractures such as undisplaced greenstick fractures and torus fractures ${ }^{20}$ and may be more sensitive than $\mathrm{x}$-ray in detecting toddler's fractures. Rather than sending the child home for delayed imaging, point of care ultrasound by trained emergency physicians has been shown to have a sensitivity of 91 to $100 \%$ and a specificity of $69 \%$ to $100 \%$ for detecting such fractures. ${ }^{21}$ It can also be used to compare sides without additional radiation. 
Ultrasonographic evidence of fracture may be visible up to three weeks earlier than radiographic evidence. $^{22}$

There are a number of challenges to the effective use of ultrasound, however, including credentialing of practitioners in non-traditional use of the technology, remuneration for services that are normally the remit of the diagnostic imaging department as well as acceptance by orthopaedic colleagues.

\section{Treating the injury}

Once the child has had adequate pain relief and the fracture visualised one must decide how best to manage it. There is some controversy how simple buckle fractures should be managed. One option is to place all such fractures in a cast. A number of small studies have suggested that a removable splint is a viable alternative ${ }^{23}$ with improved patient satisfaction and no increase in pain with the added merit that the patient will not have to deal with the potential complications of cast application. Inhalational agents such as methoxyflurane or nitrous oxide reduce the pain of applying a well molded cast if it is needed.

More displaced distal forearm fractures can be safely reduced in the emergency department under procedural sedation. Ketamine has been shown to be a safe and effective agent for this. ${ }^{24}$ In a resource limited setting, ultrasound facilitated fracture reduction may obviate the need for traditional radiography and reduce the need for further manipulation as compared to a 'blind' technique. ${ }^{25}$ Local practice varies around the decision to reduce a fracture in theatre. The Royal 
Children's Hospital, Melbourne produce a fracture guideline which is freely available online and provides a robust basis for decision making in this area. ${ }^{26}$

\section{Follow-up}

Do all undisplaced minor buckle fractures need to be seen in a specialist orthopaedic fracture clinic? Paediatric distal metaphyseal fractures invariably remodel with minimal functional sequelae. There is no change in outcome for these patients followed up in the community and it is likely to be significantly more convenient for the patient. All other fractures should be routinely reviewed in orthopaedic outpatients/fracture clinic. Parents should be warned of the potential early complications of plaster application and provided with written information about plaster care prior to discharge.

\section{Conclusion}

By taking the patient's journey, from point of impact, through the emergency department and beyond, we can see many ways that we can optimise the patient experience. Weight-based analgesia should be offered in the pre-hospital phase as well as on arrival in the department and will likely involve both opiates and non-pharmacological adjuncts such as splints and interactive distraction techniques. The use of ultrasound technology has the potential to help the emergency practitioner to diagnose minor fractures and may be used to facilitate manipulation of certain fractures under procedural sedation.

This article is protected by copyright. All rights reserved. 


\section{References}

1. British Paediatric Association, British Association of Paediatric Surgeons, Casualty Surgeons Association. Joint statement on children's attendances at accident and emergency departments. London: British Paediatric Association, 1988.

2. Clapperton A, Ashby K, Cassell E. Injury profile Victoria 2001. Hazard 2001; 54: 1-24. Available at:www.monash.edu.au/muarc/VISAR/hazard/haz54.pdf

3. Young, Simon J., Peter LJ Barnett, and Ed A. Oakley. "11. Fractures and minor head injuries: minor injuries in children II." Med J Aust 182.12 (2005): 644-648.

4. Mills E, Craig S, Oakley E. Busted! Management of paediatric upper limb fractures: not all that it's cracked up to be. Emerg Med Australas. 2014 Aug;26(4):384-91. doi: 10.1111/17426723.12265

5. Samuel, Nir, Ivan P. Steiner, and Itai Shavit. "Prehospital pain management of injured children: a systematic review of current evidence." The American journal of emergency medicine 33.3 (2015): 451-454.

6. Babl, Franz E., et al. "Inhaled methoxyflurane as a prehospital analgesic in children." Emergency Medicine Australasia 18.4 (2006): 404-410.

7. Garra, Gregory, et al. "Validation of the Wong -Baker FACES pa emergency department patients." Academic Emergency Medicine17.1 (2010): 50-54. 
8. The FLACC: a behavioral scale for scoring postoperative pain in young children. Merkel SI, Voepel-Lewis T, Shayevitz JR, Malviya S Pediatr Nurs. 1997 May-Jun; 23(3):293-7.

9. Middleton, Paul M., et al. "Effectiveness of morphine, fentanyl, and methoxyflurane in the prehospital setting." Prehospital emergency care 14.4 (2010): 439-447.

10. McGrath, Patricia A. "Development of the World Health Organization guidelines on cancer pain relief and palliative care in children." Journal of pain and symptom management 12.2 (1996): 87-92.

11. Racoosin, Judith A., et al. "New evidence about an old drug_risk with codeine after adenotonsillectomy." New England Journal of Medicine 368.23 (2013): 2155-2157.

12. Murphy, Adrian, et al. "Intranasal fentanyl for the management of acute pain in children." The Cochrane Library (2014).

13. Schacherer, Nicole Marie, et al. "Expedited Delivery of Pain Medication for Long-Bone Fractures Using an Intranasal Fentanyl Clinical Pathway." Pediatric emergency care (2015)

14. Yeaman, Fiona, et al. "Sub -dissociative dose children in the emergency department: A pilot study." Emergency Medicine Australasia 25.2 (2013): 161-167.

15. Graudins A, Meek R, Egerton-Warburton D, Oakley E, Seith R. The PICHFORK (Pain in Children Fentanyl or Ketamine) trial: a randomized controlled trial comparing intranasal ketamine and fentanyl for the relief of moderate to severe pain in children with limb injuries. Ann Emerg Med. 2015 Mar;65(3):248-254

This article is protected by copyright. All rights reserved. 
16. Kendrick JG, Carr RR, Ensom MHH. Pharmacokinetics and Drug Dosing in Obese Children. The Journal of Pediatric Pharmacology and Therapeutics

2QNP:15(2):94109.

17. O'Donnell JJ, Maurice SC, Beattie TF. Emergency analgesia in the paediatric population. Part III non-pharmacological measures of pain relief and anxiolysis. Emerg Med J 2002;19:1957 $=$

18. Wohlheiter, Karen A., and Lynnda M. Dahlquist. "Interactive versus passive distraction for acute pain management in young children: The role of selective attention and development." Journal of pediatric psychology (2012): jss108.

19. Hendee, William R., and F. Marc Edwards. "ALARA and an integrated approach to radiation protection." Seminars in nuclear medicine. Vol. 16. No. 2. WB Saunders, 1986.

20. Pountos, Ippokratis, John Clegg, and Asim Siddiqui. "Diagnosis and treatment of greenstick and torus fractures of the distal radius in children: a prospective randomised single blind study." Journal of children's orthopaedics 4.4 (2010): 321-326.

21. May, Gabrielle. "The Use of Ultrasound for Diagnosing Paediatric Wrist Fractures." BestBets.: 4 Nov. 2009. Web. Accessed 27 Sept. 2015

22. Lewis, D. and Logan, P. (2006), Sonographic diagnosis of toddler's fracture in the emergency department. J. Clin. Ultrasound, 34: 190-194

23. Milne, K. (2013, January 14). SGEM\#19: Bust-a-Move (Buckle and Greenstick Fractures). Retrieved October 2, 2015, from http://thesgem.com/2013/01/sgem19-bust-a-movel

24. Howes, M. "Ketamine for paediatric sedation/analgesia in the emergency department." Emergency medicine journal: EMJ 21.3 (2004): 275

This article is protected by copyright. All rights reserved. 
25. Wellsh, Bobby M., and Jerzy M. Kuzma. "Ultrasound-Guided Pediatric Forearm Fracture Reductions in a Resource-Limited Emergency Department." The American Journal of Emergency Medicine (2015)

26. The Royal Children's Hospital Melbourne. (n.d.). Retrieved October 2, 2015, from http://www.rch.org.au/clinicalguide/fractures/

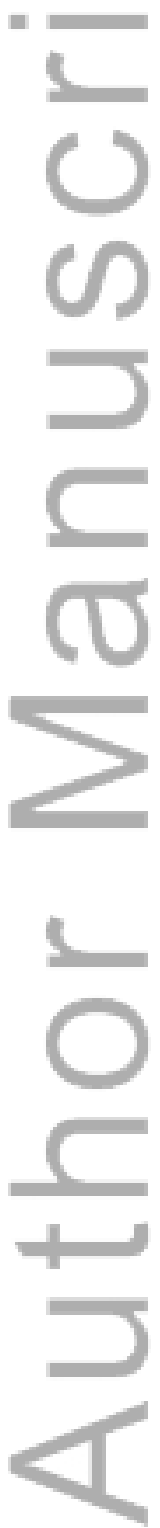

This article is protected by copyright. All rights reserved. 


\section{University Library}

\section{- M M N E R VA A gateway to Melbourne's research publications}

Minerva Access is the Institutional Repository of The University of Melbourne

Author/s:

Tagg, A;Goldstein, H;Davis, T;Lawton, B

Title:

Sticks and stones may break some bones

Date:

2016-02-01

Citation:

Tagg, A., Goldstein, H., Davis, T. \& Lawton, B. (2016). Sticks and stones may break some bones. EMERGENCY MEDICINE AUSTRALASIA, 28 (1), pp.4-6. https:// doi.org/10.1111/1742-6723.12531.

Persistent Link:

http://hdl.handle.net/11343/290831 